\title{
Problematic Social Networking Site Use: A Brief Review of Recent Research Methods and the Way Forward
}

\author{
Zaheer Hussain $^{1 *}$ and Vladan Starcevic ${ }^{2}$
}

${ }^{1}$ School of Social Sciences, Nottingham Trent University, UK

${ }^{2}$ University of Sydney, Faculty of Medicine and Health, Sydney Medical School, Nepean

Clinical School, Discipline of Psychiatry, Sydney, NSW, Australia

$$
\text { *corresponding author }
$$

\section{Highlights}

- Problematic social networking site use has been widely researched.

- Cross-sectional studies are common, but they have significant limitations.

- An integration of research methods and setting a research agenda is needed. 


\title{
Problematic Social Networking Site Use: A Brief Review of Recent Research Methods
}

\section{and the Way Forward}

\begin{abstract}
Social networking site (SNS) use is a routine activity for millions of people around the world. Under certain circumstances, an increase in SNS use may lead to problematic social networking site use (PSNSU). Numerous studies have reported associations between PSNSU and various psychosocial variables. The present review briefly examines research methods that have been employed to investigate PSNSU. Cross-sectional studies have been a popular method of investigating PSNSU, but they have significant limitations. Longitudinal and neuroimaging studies may provide important insights, but they are more difficult to conduct and have been less utilised. The field would benefit from a clarification of research priorities, integration of research methods, and studies that include SNS users from various age groups.
\end{abstract}

Key words: problematic social networking site use, behavioural addictions, research methods, longitudinal studies, neuroimaging 


\section{Introduction}

The use of social networking sites (SNSs) has increased considerably over the past decade and has become an integral part of daily life for a large proportion of the world's population. There are over 2 billion SNS users worldwide [1], and the numbers of worldwide SNS users is set to rise with SNS use rapidly increasing in countries such as China [2]. SNSs allow users to share information, post and view videos, pictures, comments, and messages. As of January 2020, Facebook had more than 2.45 billion monthly active users, YouTube had 2 billion monthly active users, the photo-sharing SNS Instagram had 1 billion monthly active users, while the newest popular SNS, TikTok, had 800 million monthly active users [3]. Alongside this popularity of SNSs, some users develop a pattern of problematic SNS use (PSNSU). In its most extreme form, PSNSU has been considered a behavioural addiction by some researchers $[4,5]$. Therefore, it is important to examine how research has contributed to our understanding of problematic social networking behaviour.

PSNSU is a relatively recent phenomenon and there are controversies as to how best to conceptualise it. Unlike Internet gaming disorder/gaming disorder, this online behaviour is not listed in DSM-5 or ICD-11 as a provisional or official diagnostic category. Similar to problematic gaming, drawing the boundary between normal use of SNSs and PSNSU has not been easy. Furthermore, different terms have been used in reference to PSNSU, which further complicates communication between researchers and understanding of this behaviour. Examples include "Facebook addiction" [6], "addictive use of social networking sites" [7] and "Internet-communication disorder" [8]. Complicating matters further, terms like "smartphone use disorder" or "smartphone addiction" have been used to refer to PSNSU or in the context of PSNSU because most of social networking takes place via smartphones. In a recent article, Montag, Wegmann, Sariyska, Demetrovics, and Brand [9] proposed the term "Internet communication/social networks use disorder" as a subtype of a broader category 
"Internet use disorders". However, what constitutes a "disorder" and whether PSNSU qualifies for a disorder remains debatable. For these reasons, we prefer to use the term PSNSU throughout the present article, although we retain the original terminology used by the authors of various studies.

The aim of this brief review is to examine research methods that have recently (20182020) been used to investigate PSNSU. We have identified survey, longitudinal and neuroimaging studies, as well as a number of studies using other research methods. A discussion of future research methods and perspectives in this domain will also be presented.

\section{Survey studies}

Many studies have used cross-sectional, self-report survey methods to investigate PSNSU. These studies and their findings are presented in Table 1. The majority of studies were conducted in Europe, with sample sizes ranging from 152 to 1157. Study participants were mostly younger individuals, with only one study reporting an age range of up to 64 years. In one study, PSNSU was a categorical or dichotomous variable, with it being recorded as present or absent [10], whereas in 14 studies, PSNSU was a continuous variable, allowing its severity to be assessed. Likewise, the investigated constructs (e.g., anxiety and depression) were included as a dichotomous or diagnostic variable such as major depressive disorder in 12 studies studies or as a continuous variable in three studies.

Given the methodology of survey studies, most of them reported associations between various constructs and PSNSU severity. Thus, PSNSU severity has been associated with anxiety [11, 12], social anxiety [13], stress [11], poor sleep quality [11], depressive symptoms [14], depression [12], major depressive disorder [15], impulsivity [16], rumination [17], lower interpersonal trust [14], cyberbullying perpetration [18], fear of missing out [17], 
belongingness [18], social connectedness [18], extraversion [16], social norms [19], SNS use frequency [17], friends' SNS use [19], low family functioning [14], difficulties in emotion regulation [19], neuroticism [16], poor recognition of negative emotions [20], and conscientiousness [16]. Reported predictors of PSNSU severity include younger age [21, 18], anxiety [21], social anxiety [22], stress [12], ADHD symptoms [23], covert narcissism [24], smartphone addiction [24], problematic internet use [24], being in a relationship [21], parasocial relationships with SNS users [22], low positive emotion recognition [20] and low selfesteem [24]. In one study, narcissism and Machiavellianism were associated with PSNSU [10].

Many of these relationships may be nonspecific for PSNSU and their "discovery" depends on the type of variables that are examined. Moreover, only a few variables have been found to be associated with PSNSU severity in more than one study, suggesting a lack of consistency between findings of various studies. Another limitation of survey studies is a reliance on data obtained from self-report instruments. Finally, cross-sectional survey studies cannot point to the direction of any causality between PSNSU and other variables. Survey studies allow a large amount of data to be collected relatively quickly and conveniently, which largely explains their popularity. However, this research method may be overused.

A few survey studies reflect a promising trend of going beyond associations. For example, one study estimated the prevalence of PSNSU severity [14], while another study examined PSNSU severity and anxiety related to use of SNSs across generations, in mothers and their offspring [13]. A survey method has also been used to study the interplay between ADHD symptoms and time perspective in PSNSU severity [23] and the role of emotion recognition in the development of PSNSU [20]. The latter study provided useful recommendations for therapeutic interventions. 


\section{Longitudinal studies}

Seven longitudinal studies of PSNSU and their findings are presented in Table 2. Five of these studies were conducted in Europe. Sample sizes ranged from 209 to 4237 and younger individuals were participants in most studies. Only one study reported an age range of up to 71 years. The follow-up periods ranged from 6 weeks to 3 years.

Longitudinal studies revealed various associations between PSNSU severity and different variables. It appears that PSNSU severity and depression may have a bi-directional relationship, as two studies reported that PSNSU severity predicted depression [25**, 26**], whereas one study suggested that depression was a risk factor for developing PSNSU [27]. PSNSU also predicted insomnia [25**] and suicide-related outcomes [28**] and exacerbated ADHD symptoms [29*]. One study reported that increased PSNSU severity was associated positively with neuroticism and negatively with conscientiousness [30]. Duration of daily Facebook use was a significant predictor of addictive Facebook use [25**]. Interestingly, one study demonstrated that although different motivations for SNS use (alleviating boredom or seeking social connectedness) could both lead to PSNSU and anxiety, other outcomes might be different [31].

The advantage of longitudinal studies is that they provide valuable data about the course of PSNSU and possible causal associations between PSNSU severity and psychological and psychopathological variables. Longitudinal studies have been more likely to identify individuals with PSNSU and follow them up over a period of time than to use PSNSU as an outcome variable. Therefore, there are more data about the course of PSNSU than about risk and aetiological factors for PSNSU. One disadvantage of the longitudinal approach is the inevitable participant attrition over time. Another disadvantage is a need to 
control for various factors other than the passage of time. Taken together, longitudinal studies have provided good insights in to PSNSU behaviour, this is a method which should be utilised more often.

\section{Neuroimaging studies}

Table 3 presents the only two neuroimaging studies conducted over the past two years. Both studies were conducted in the USA by the same group of researchers and in small samples (20 and 32) [32, 33]. The age range of study participants across both studies was between 18 and 62 years, with most participants belonging to a younger age group.

Neuroimaging methods can provide unique insights into PSNSU. Findings of neuroimaging studies of PSNSU severity are similar to those of neuroimaging studies of substance addiction. However, these findings are mostly about the associations of various brain structures with PSNSU severity, providing data about the correlates, not the causes, of PSNSU. A more useful approach would be to combine neuroimaging and longitudinal study methods and compare the findings at different points in time.

\section{Other research methods}

Nine studies used various other research methods to investigate PSNSU and their findings are presented in Table 4. Four of these studies were conducted in the USA and three were conducted in Europe. Sample sizes ranged from 38 to 615 and participants were mainly younger individuals.

Two studies used both quantitative and qualitative research methods; one study reported that mindfulness decreased PSNSU-derived stress [34*], the other study reported 
that participants experienced "near addiction" or "social media addiction" symptoms [35]. Three studies found associations between PSNSU severity and neuroticism [36], risk-taking [37**], and implicit attitude [38] utilising an artificial neural network approach, the Balloon Analogue Risk Task, and Facebook Implicit Association Test, respectively. Using an experimental design, another study demonstrated that participants who were "addicted" to Facebook discounted delayed rewards more quickly than non-addicted control participants [39]. One study found that increased duration of Facebook use did not correlate with eyetracking measures but were associated with increased Facebook addiction severity and depression scores [40]. Finally, two intervention studies reported favourable outcomes in terms of reducing PSNSU severity and improving well-being [41**, 42**].

Taken together, studies that utilised other research methods have provided a few new insights into PSNSU. This is not a consequence of any inherent weaknesses of the research methodology used in these studies but reflects the fact that these approaches are relatively novel. Therefore, more studies using the same research methods should be conducted for their proper evaluation. This particularly applies to intervention studies of PSNSU, which are sorely needed.

\section{Conclusion}

The present review demonstrates that various research methods used in the research on PSNSU have both advantages and limitations. Based on the number of studies, crosssectional survey studies seem to be most popular, which is largely due to the ease with which they can be conducted. However, insights from these studies are rather limited. Longitudinal studies are more difficult to conduct and present their own methodological challenges, but they provide insights about the course of PSNSU and possible aetiological relationships 
between PSNSU and various variables. Both cross-sectional and longitudinal studies have relied mainly on younger samples, especially students. Neuroimaging and other research methods are promising, but like most other approaches, they would benefit from a better integration with other methods.

In addition to integration of methods (for example, combining the longitudinal and neuroimaging approaches, as already suggested), the field would benefit from setting a research agenda that would outline research priorities. These priorities would be based on theoretical understanding so far and knowledge gained from the research conducted up to this point. For example, one priority is elucidation of the relationship between PSNSU and other addictive behaviours (whether or not substance-related). Another area is a systematic study of how depression and other specific psychopathology relate to PSNSU. It would also be important to study biological and neurobiological correlates (and potential biomarkers) of PSNSU. In addition, little is known about PSNSU in middle and late adulthood and future studies should aim to recruit more participants from this age group. Once these priorities have been set, it should be easier for researchers worldwide to collaborate on projects aiming to improve our understanding of PSNSU.

\section{Credit Author Statement}

Zaheer Hussain: Conceptualisation, Writing - Original Draft, Writing - Review \& Editing. Vladan Starcevic: Writing - Review \& Editing.

\section{Declaration of interests}

The authors declare that they have no known competing financial interests or personal relationships that could have appeared to influence the work reported in this paper. 


\section{References}

[1] Hussain, Z., \& Griffiths, M. D. Problematic social networking site use and comorbid psychiatric disorders: A systematic review of recent large-scale studies. Front Psych, 2018. Doi: 10.3389/fpsyt.2018.00686

[2] Hussain, Z., Wegmann, E., Yang, H., \& Montag, C. Social Networks Use Disorder and Associations with Depression and Anxiety Symptoms: A Systematic Review of Recent Research in China. Front Psychol, 2020. Doi: 10.3389/fpsyg.2020.00211

[3] Statista.com. Most popular social networks worldwide as of January 2020, ranked by number of active users. 2020. Retrieved March 13, 2020, from:

https://www.statista.com/statistics/272014/global-social-networks-ranked-by-number-ofusers/

[4] Andreassen, C. S., Torsheim, T., Brunborg, G. S., \& Pallesen, S. Development of a Facebook Addiction Scale. Psychol Rep, 2012. Doi: 10.2466/02.09.18.PR0.110.2.501-517

[5] Griffiths, M. D., Kuss, D. J., \& Demetrovics, Z. Social networking addiction: An overview of preliminary findings. In: Rosenberg, K.P., Feder, L.C., editors. Behavioral addictions: Criteria, evidence, and treatment (pp. 119-141). London: Academic, 2014.

[6] Ryan, T., Chester, A., Reece, J., and Xenos, S. The uses and abuses of Facebook: a review of Facebook addiction. J. Behav. Addict, 2014. Doi: 10.1556/JBA.3.2014.016

[7] Wegmann, E., Stodt, B., and Brand, M. Addictive use of social networking sites can be explained by the interaction of Internet use expectancies, Internet literacy, and psychopathological symptoms. J. Behav. Addict, 2015. Doi: 10.1556/2006.4.2015.021

[8] Wegmann, E., \& Brand, M. Internet-communication disorder: It's a matter of social aspects, coping, and Internet-use expectancies. Front Psychol, 2016. Doi:10.3389/ fpsyg.2016.01747

[9] Montag, C., Wegmann, E., Sariyska, R., Demetrovics, Z., \& Brand, M. How to overcome taxonomical problems in the study of Internet use disorders and what to do with "smartphone addiction"?. J. Behav. Addict, 2020. Doi: 10.1556/2006.8.2019.59

[10] Kircaburun, K., Demetrovics, Z., \& Tosuntaş, Ş. B. Analyzing the links between problematic social media use, Dark Triad traits, and self-esteem. Int J. Ment Health Addict, 2019. Doi: 10.1007/s11469-018-9900-1

[11] Atroszko, P. A., Balcerowska, J. M., Bereznowski, P., Biernatowska, A., Pallesen, S., \& Andreassen, C. S. Facebook addiction among Polish undergraduate students: Validity of measurement and relationship with personality and well-being. Comput Hum Behav, 2018. Doi: 10.1016/j.chb.2018.04.001

[12] Verseillié, É., Laconi, S., \& Chabrol, H. Pathological Traits Associated to Facebook and Twitter among French Users. Int J. Environ Res Pub Health, 2020. Doi: 10.3390/ijerph17072242

[13] Ruggieri, S., Santoro, G., Pace, U., Passanisi, A., \& Schimmenti, A. Problematic Facebook use and anxiety concerning use of social media in mothers and their offspring: An 
actor-partner interdependence model. Addict Behav Rep, 2020. Doi: 10.1016/j.abrep.2020.100256

[14] Wartberg, L., Kriston, L., \& Thomasius, R. Internet gaming disorder and problematic social media use in a representative sample of German adolescents: Prevalence estimates, comorbid depressive symptoms and related psychosocial aspects. Comput Hum Behav, 2020. Doi: 10.1016/j.chb.2019.09.014

[15] Robinson, A., Bonnette, A., Howard, K., Ceballos, N., Dailey, S., Lu, Y. \& Grimes, T. Social comparisons, social media addiction, and social interaction: An examination of specific social media behaviors related to major depressive disorder in a millennial population. J. App Biobehav Res, 2019. Doi:10.1111/jabr.12158

[16] Sindermann, C., Elhai, J. D., \& Montag, C. Predicting tendencies towards the disordered use of Facebook's social media platforms: On the role of personality, impulsivity, and social anxiety. Psychi Res, 2020. Doi: 10.1016/j.psychres.2020.112793

[17] Dempsey, A. E., O'Brien, K. D., Tiamiyu, M. F., \& Elhai, J. D. Fear of missing out (FoMO) and rumination mediate relations between social anxiety and problematic Facebook use. Addict Behav Rep, 2019. Doi: 10.1016/j.abrep.2018.100150

[18] Kircaburun, K., Kokkinos, C. M., Demetrovics, Z., Király, O., Griffiths, M. D., \& Çolak, T. S. Problematic online behaviors among adolescents and emerging adults: Associations between cyberbullying perpetration, problematic social media use, and psychosocial factors. Int J. Ment Health Addict, 2018. Doi: 10.1007/s11469-018-9894-8

[19] Marino, C., Gini, G., Angelini, F., Vieno, A., \& Spada, M. M. Social norms and emotions in problematic social media use among adolescents. Addict Behav Rep, 2020. Doi: 10.1016/j.abrep.2020.100250

[20] Ünal-Aydın, P., Balikçi, K., Sönmez, İ., \& Aydın, O. Associations between emotion recognition and social networking site addiction. Psychi Res, 2019. Doi:

10.1016/j.psychres.2019.112673

[21] Hussain, Z., \& Griffiths, M. D. The Associations between Problematic Social Networking Site Use and Sleep Quality, Attention-Deficit Hyperactivity Disorder, Depression, Anxiety and Stress. Int J. Ment Health Addict, 2019. Doi: 10.1007/s11469-01900175-1

[22] de Bérail, P., Guillon, M., \& Bungener, C. The relations between YouTube addiction, social anxiety and parasocial relationships with YouTubers: A moderated-mediation model based on a cognitive-behavioral framework. Comput Hum Behav, 2019. Doi: 10.1016/j.chb.2019.05.007

[23] Settanni, M., Marengo, D., Fabris, M. A., \& Longobardi, C. The interplay between ADHD symptoms and time perspective in addictive social media use: a study on adolescent Facebook users. Child Youth Serv Rev, 2018. Doi: 10.1016/j.childyouth.2018.04.031

[24] Liu, C., \& Ma, J. Development and validation of the Chinese social media addiction scale. Pers Indiv Diff, 2018. Doi: 10.1016/j.paid.2018.05.046 
[25] **Brailovskaia, J., Rohmann, E., Bierhoff, H. W., Margraf, J., \& Köllner, V.

Relationships between addictive Facebook use, depressiveness, insomnia, and positive mental health in an inpatient sample: A German longitudinal study. J. Behav. Addict, 2019. Doi: 10.1556/2006.8.2019.63. A longitudinal study conducted in a clinical setting. Regression analyses revealed that duration of daily Facebook use at baseline was a significant predictor of addictive Facebook use after 6 weeks. Addictive Facebook use at baseline significantly predicted depressiveness and insomnia after 6 weeks.

[26] ** Raudsepp, L. Brief report: Problematic social media use and sleep disturbances are longitudinally associated with depressive symptoms in adolescents. J. Adolesc, 2019. Doi: 10.1016/j.adolescence.2019.09.005. A two-year longitudinal study which revealed associations between problematic social networking site use and depressive symptoms.

[27] Li, J. B., Mo, P. K., Lau, J. T., Su, X. F., Zhang, X., Wu, A. M., ... \& Chen, Y. X. Online social networking addiction and depression: The results from a large-scale prospective cohort study in Chinese adolescents. J. Behav. Addict, 2018. Doi: 10.1556/2006.7.2018.69

[28] **Brailovskaia, J., Teismann, T., \& Margraf, J. Positive Mental Health Mediates the Relationship Between Facebook Addiction Disorder and Suicide-Related Outcomes: A Longitudinal Approach. Cyberpsy Behav Soc Net, 2020. Doi: 10.1089/cyber.2019.0563. A one-year longitudinal study of German Facebook users. The results revealed associations between 'Facebook addiction disorder' and suicide-related outcomes.

[29] *Boer, M., Stevens, G., Finkenauer, C. and van den Eijnden, R. Attention deficit hyperactivity disorder-symptoms, social media use intensity, and social media use problems in adolescents: Investigating directionality. Child Dev, 2019. Doi:

10.1111/cdev.13334. This study utilised a three-wave longitudinal method in Dutch adolescents. The findings revealed a unidirectional relationship, whereby PSNSU increased ADHD symptoms over time, while intensity of SNS use did not have such an effect.

[30] Bouna-Pyrrou, P., Aufleger, B., Braun, S., Gattnar, M., Kallmayer, S., Wagner, H., ... \& Lenz, B. Cross-sectional and longitudinal evaluation of the social network use disorder and internet gaming disorder criteria. Front Psychi, 2018. Doi: 10.3389/fpsyt.2018.00692

[31] **Stockdale, L. A., \& Coyne, S. M. Bored and online: Reasons for using social media, problematic social networking site use, and behavioral outcomes across the transition from adolescence to emerging adulthood. J. Adolesc, 2020. Doi:

10.1016/j.adolescence.2020.01.010. A longitudinal study examining motivations for social networking site use across three years during the transition from late adolescence to emerging adulthood.

[32] He, Q., Turel, O., \& Bechara, A. Association of excessive social media use with abnormal white matter integrity of the corpus callosum. Psychi Res Neuro, 2018. Doi: 10.1016/j.pscychresns.2018.06.008

[33] **Turel, O., He, Q., Brevers, D., \& Bechara, A. Delay discounting mediates the association between posterior insular cortex volume and social media addiction symptoms. Cogn Affect, Behav Neurosc, 2018. Doi: 10.3758/s13415-018-0597-1. This study provided initial evidence that insular morphology could be associated with PSNSU. 
[34] *Apaolaza, V., Hartmann, P., D'Souza, C., \& Gilsanz, A. Mindfulness, Compulsive Mobile Social Media Use, and Derived Stress: The Mediating Roles of Self-Esteem and Social Anxiety. Cyberpsy Behav Soc Net, 2019. Doi: 10.1089/cyber.2018.0681. This study used qualitative (focus groups) and quantitative (surveys) methods to investigate mindfulness and PSNSU to develop a conceptual model.

[35] Grau, S., Kleiser, S., \& Bright, L. Exploring social media addiction among student Millennials. Qual Mar Res Int J., 2019. Doi:10.1108/QMR-02-2017-0058

[36] Leong, L. Y., Hew, T. S., Ooi, K. B., Lee, V. H., \& Hew, J. J. A hybrid SEM-neural network analysis of social media addiction. Exp Sys App, 2019. Doi:

10.1016/j.eswa.2019.05.024

[37] **Meshi, D., Ulusoy, E., Özdem-Mertens, C., Grady, S. M., Freestone, D. M., Eden, A., \& Ellithorpe, M. E. Problematic social media use is associated with increased riskaversion after negative outcomes in the Balloon Analogue Risk Task. Psych Addict Behav, 2020. Doi: 10.1037/adb0000558. This recent study used a novel task (Balloon Analogue Risk Task) to investigate risky decision making and PSNSU.

[38] Turel, O., \& Serenko, A. Cognitive biases and excessive use of social media: The facebook implicit associations test (FIAT). Addict Behav, 2020. Doi:

10.1016/j.addbeh.2020.106328

[39] Delaney, D., Stein, L. A. R., \& Gruber, R. Facebook addiction and impulsive decisionmaking. Addict Res Theo, 2018. Doi: 10.1080/16066359.2017.1406482

[40] Hussain, Z., Simonovic, B., Stupple, E. J., \& Austin, M. Using eye tracking to explore facebook use and associations with facebook addiction, mental well-being, and personality. Behav Sci, 2019. doi: 10.3390/bs9020019

[41] **Brailovskaia, J., Ströse, F., Schillack, H., \& Margraf, J. Less Facebook use-More well-being and a healthier lifestyle? An experimental intervention study. Comput Hum Behav, 2020. Doi: 10.1016/j.chb.2020.106332. This experimental intervention study reported that a reduction in daily Facebook use led to a better well-being and healthier lifestyle.

[42] ** Hou, Y., Xiong, D., Jiang, T., Song, L., \& Wang, Q. Social media addiction: Its impact, mediation, and intervention. Cyberpsychology: J. Psycho Res Cyber, 2019. Doi: 10.5817/CP2019-1-4. This study investigated the associations between PSNSU, mental health and academic performance and further tested the effectiveness of an intervention for reducing PSNSU and its adverse outcomes.

$*$ of interest
$* *$ of outstanding interest 
Table 1. Overview of survey studies

\begin{tabular}{|c|c|c|c|c|}
\hline Authors & Country & Sample size & Age (years) & Findings \\
\hline Atroszko et al., (2018) & Poland & 1,157 & Mean $=20.33$ & $\begin{array}{l}\text { Positive and significant association between PSNSU severity, } \\
\text { anxiety, and stress. PSNSU severity was associated with } \\
\text { impoverished well-being and decreased sleep quality. }\end{array}$ \\
\hline de Bérail et al., (2019) & France & 932 & Mean $=21.25$ & $\begin{array}{l}\text { Social anxiety and para-social relationships with SNS users are } \\
\text { predictors of PSNSU severity. Social anxiety moderates the } \\
\text { relationship between para-social relationships and PSNSU } \\
\text { severity. }\end{array}$ \\
\hline $\begin{array}{l}\text { Dempsey, O’Brien, } \\
\text { Tiamiyu, and Elhai (2019) }\end{array}$ & USA & 291 & Mean $=20.03$ & $\begin{array}{l}\text { FoMO and rumination were significantly associated with PFU } \\
\text { severity. Facebook use frequency was associated with PFU } \\
\text { severity. }\end{array}$ \\
\hline $\begin{array}{l}\text { Hussain and Griffiths } \\
\text { (2019) }\end{array}$ & UK & 638 & Mean $=32.03$ & $\begin{array}{l}\text { Age, being in a relationship, and anxiety explained } 23.9 \% \text { of the } \\
\text { variance in PSNSU severity. }\end{array}$ \\
\hline $\begin{array}{l}\text { Kircaburun, Demetrovics, } \\
\text { and Tosuntaş (2019) }\end{array}$ & Turkey & 827 & Range $=17-24$ & $\begin{array}{l}\text { Machiavellianism and narcissism had small significant direct } \\
\text { effects on PSNSU. }\end{array}$ \\
\hline Kircaburun et al., (2018) & Turkey & $\begin{array}{l}\text { Study 1: } 1,143 \\
\text { Study 2: } 760\end{array}$ & $\begin{array}{l}\text { Study } 1 \text { Range }=14-21 \\
\text { Study } 2 \text { Range }=18-40\end{array}$ & $\begin{array}{l}\text { PSNSU severity and cyberbullying perpetration were directly } \\
\text { associated with each other. Belongingness (directly) and social } \\
\text { connectedness (indirectly) were both associated with } \\
\text { cyberbullying perpetration and PSNSU severity. Age was a } \\
\text { significant direct predictor of PSNSU severity. }\end{array}$ \\
\hline Liu and Ma (2018) & China & 619 & Range $=16-28$ & $\begin{array}{l}\text { Smartphone addiction, covert narcissism and increasing daily use } \\
\text { were all key predictors of PSNSU severity - explaining } 40 \% \text { of } \\
\text { the total variance related to PSNSU. }\end{array}$ \\
\hline $\begin{array}{l}\text { Marino, Gini, Angelini, } \\
\text { Vieno, and Spada (2020) }\end{array}$ & Italy & 761 & Range $=13-19$ & $\begin{array}{l}\text { Social norms were directly associated with PSNSU and friends' } \\
\text { SNS use was associated with the frequency of SNS use, which, in } \\
\text { turn, was associated with PSNSU severity. Difficulties in } \\
\text { emotion regulation were directly and indirectly linked to PSNSU } \\
\text { severity via frequency of use and facilitating use of e-motions. }\end{array}$ \\
\hline Robinson et al., (2019) & USA & 504 & Range $=18-38$ & $\begin{array}{l}\text { High PSNSU severity scores was significantly associated with } \\
\text { major depressive disorder. }\end{array}$ \\
\hline
\end{tabular}




\begin{tabular}{|l|c|c|c|l|}
\hline $\begin{array}{l}\text { Ruggieri, Santoro, Pace, } \\
\text { Passanisi, \& Schimmenti, } \\
\text { 2020) }\end{array}$ & Italy & 152 & $\begin{array}{c}\text { Mean age of mothers }= \\
43.70, \text { Mean age of } \\
\text { offspring }=13.70\end{array}$ & $\begin{array}{l}\text { Positive association between PSNSU severity levels in mothers } \\
\text { and PSNSU severity levels in offspring. PSNSU severity levels } \\
\text { were associated with SNS social anxiety in offspring. }\end{array}$ \\
\hline $\begin{array}{l}\text { Settanni, Marengo, Fabris, } \\
\text { and Longobardi, (2018) }\end{array}$ & Italy & 283 & Mean $=15.28$ & $\begin{array}{l}\text { ADHD symptoms positively predicted } \\
\text { PSNSU severity, past negative and present fatalistic orientation } \\
\text { and negatively predicted future orientation. Past negative and } \\
\text { present fatalistic time perspective orientations acted as mediators } \\
\text { of the relationship between ADHD symptoms and PSNSU } \\
\text { severity. }\end{array}$ \\
\hline $\begin{array}{l}\text { Sindermann, Elhai, and } \\
\text { Montag (2020) }\end{array}$ & Germany & 494 & $\begin{array}{l}\text { Mean }=24.72 \\
\text { Range }=12-55\end{array}$ & $\begin{array}{l}\text { Impulsivity and extraversion were associated with SNS use } \\
\text { disorder. Conscientiousness and neuroticism were associated } \\
\text { with Facebook use disorder. }\end{array}$ \\
\hline $\begin{array}{l}\text { Ünal-Aydin, Balikçi, } \\
\text { Sönmez, \& Aydin, 2019) }\end{array}$ & Bosnia and & 337 & $\begin{array}{l}\text { Problematic group } \\
\text { mean }=21.11, \text { non- } \\
\text { problematic group } \\
\text { mean }=21.74\end{array}$ & $\begin{array}{l}\text { PSNSU severity was associated with poor recognition of negative } \\
\text { emotions. Low positive emotion recognition predicted PSNSU } \\
\text { severity. }\end{array}$ \\
\hline $\begin{array}{l}\text { Verseillié, Laconi, and } \\
\text { Chabrol (2020) }\end{array}$ & France & 1,068 & Range $=18-64$ & $\begin{array}{l}\text { Problematic Facebook and Twitter use were associated with } \\
\text { depression and anxiety. Only stress explained Problematic } \\
\text { Facebook use. }\end{array}$ \\
\hline $\begin{array}{l}\text { Wartberg, Kriston, and } \\
\text { Thomasius, (2020) }\end{array}$ & Germany & 1,001 & Range $=12-17$ & $\begin{array}{l}\text { One-year prevalence of PSNSU severity was 2.6\%. 34.6\% of } \\
\text { participants with PSNSU reported depressive symptoms. More } \\
\text { depressive symptoms, lower interpersonal trust and lower family } \\
\text { functioning were statistically significantly associated with } \\
\text { PSNSU severity. }\end{array}$ \\
\hline
\end{tabular}

ADHD: Attention deficit hyperactivity disorder, FoMO: Fear of missing out, PFU: Problematic use of Facebook, PSNSU: Problematic social networking site use, SNS: Social networking site. 
Table 2. Overview of longitudinal studies

\begin{tabular}{|c|c|c|c|c|}
\hline Authors & Country & Sample size & Age (years) & Findings \\
\hline $\begin{array}{l}\text { Boer, Stevens, } \\
\text { Finkenauer, and van } \\
\text { den Eijnden (2019) }\end{array}$ & The Netherlands & 543 & Range $=11-15$ & $\begin{array}{l}\text { PSNSU severity increased ADHD symptoms over time, whereas intensity of } \\
\text { SNS use did not affect ADHD symptoms. }\end{array}$ \\
\hline $\begin{array}{l}\text { Bouna-Pyrrou et al., } \\
\text { (2018) }\end{array}$ & Germany & 307 & Range $=27-49$ & $\begin{array}{l}\text { PSNSU severity levels increased after two years. Increase in PSNSU severity } \\
\text { levels was associated positively with neuroticism and negatively with } \\
\text { conscientiousness. }\end{array}$ \\
\hline $\begin{array}{l}\text { Brailovskaia, } \\
\text { Rohmann, Bierhoff, } \\
\text { Margraf, and Kollner } \\
\text { (2019) }\end{array}$ & Germany & 349 & Range $=19-71$ & $\begin{array}{l}\text { Duration of daily Facebook use at baseline was a significant positive predictor } \\
\text { of addictive Facebook use after } 6 \text { weeks. Addictive Facebook use at baseline } \\
\text { significantly predicted depressiveness and insomnia after } 6 \text { weeks. }\end{array}$ \\
\hline $\begin{array}{l}\text { Brailovskaia, } \\
\text { Teismann, and } \\
\text { Margraf (2020) }\end{array}$ & Germany & 209 & Range $=18-41$ & $\begin{array}{l}\text { A significant positive association between FAD severity at baseline and } \\
\text { suicide-related outcomes after one year. Positive mental health negatively } \\
\text { mediated the association between FAD severity and suicide-related outcomes. }\end{array}$ \\
\hline Li et al. (2018) & China & 4,237 & Mean $=13.9$ & $\begin{array}{l}\text { Adolescents who were depressed but free of PSNSU at baseline were } 1.48 \\
\text { times more likely to develop PSNSU at follow-up compared with those who } \\
\text { were not depressed at baseline. PSNSU was accompanied by increased levels } \\
\text { of depression. }\end{array}$ \\
\hline Raudsepp (2019) & Estonia & 249 & Mean $=15.3$ & $\begin{array}{l}\text { Initial levels of PSNSU severity and sleep disturbances both significantly } \\
\text { predicted an increase in depressive symptoms. }\end{array}$ \\
\hline $\begin{array}{l}\text { Stockdale and Coyne } \\
\text { (2020) }\end{array}$ & USA & 385 & Range $=17-19$ & $\begin{array}{l}\text { Initial levels of SNS use to alleviate boredom were associated with PSNSU } \\
\text { severity, financial stress, anxiety, and empathy } 3 \text { years later. Increase in SNS } \\
\text { use to socially connect over time was related to PSNSU severity, anxiety, } \\
\text { delinquency and empathy } 3 \text { years later. }\end{array}$ \\
\hline
\end{tabular}

ADHD: Attention deficit hyperactivity disorder, FAD: Facebook addiction disorder, PSNSU: Problematic social networking site use, SNS: Social networking site. 
Table 3. Overview of neuroimaging studies

\begin{tabular}{|l|c|c|c|l|}
\hline \multicolumn{1}{|c|}{ Authors } & Country & Sample size & Age (years) & \multicolumn{1}{c|}{ Findings } \\
\hline $\begin{array}{l}\text { He, Turel, and } \\
\text { Bechara (2018) }\end{array}$ & USA & 20 & Range = 18-23 & $\begin{array}{l}\text { PSNSU severity was associated with increased mean diffusivity in the } \\
\text { body and splenium subregions of the corpus callosum. PSNSU severity } \\
\text { was associated with inter-hemispheric white matter connection deficits. }\end{array}$ \\
\hline $\begin{array}{l}\text { Turel, He, } \\
\text { Brevers, and } \\
\text { Bechara (2018) }\end{array}$ & USA & 32 & Range = 21-62 & $\begin{array}{l}\text { Gray matter volumes of the bilateral posterior insula were negatively } \\
\text { associated with PSNSU severity symptoms. This association was } \\
\text { mediated by delay discounting. Insular morphology can be associated } \\
\text { with PSNSU severity, in part, through its association with poor foresight } \\
\text { and impulsivity. }\end{array}$ \\
\hline
\end{tabular}

PSNSU: Problematic social networking site use. 
Table 4. Overview of studies using other research methods

\begin{tabular}{|c|c|c|c|c|}
\hline Authors & Country & Sample size & Age (years) & Findings \\
\hline $\begin{array}{l}\text { Apaolaza, Hartmann, } \\
\text { D'Souza, \& Gilsanz (2019) }\end{array}$ & Spain & 346 & $\begin{array}{l}\text { Mean }=18.73 \\
\text { Range }=17-26\end{array}$ & Mindfulness decreased PSNSU severity-derived stress. \\
\hline $\begin{array}{l}\text { Brailovskaia, Ströse, } \\
\text { Schillack, and Margraf } \\
\text { (2020) }\end{array}$ & Germany & 286 & $\begin{array}{l}\text { Experimental group: } \\
\text { Mean }=24.15 \\
\text { Range }=18-51 \\
\text { Control group: } \\
\text { Mean = 25.39 } \\
\text { Range }=18-59\end{array}$ & $\begin{array}{l}\text { The study intervention reduced active and passive Facebook use, Facebook use } \\
\text { intensity and the level of FAD severity. }\end{array}$ \\
\hline $\begin{array}{l}\text { Delaney, Stein, and Gruber } \\
\text { (2018) }\end{array}$ & USA & 75 & Mean $=19.80$ & $\begin{array}{l}\text { Facebook-addicted participants discounted delayed rewards more quickly than } \\
\text { non-addicted control participants. Those addicted to Facebook were more } \\
\text { impulsive than those who were not addicted to Facebook. }\end{array}$ \\
\hline $\begin{array}{l}\text { Grau, Kleiser, and Bright } \\
(2019)\end{array}$ & USA & 129 & Range $=19-22$ & $\begin{array}{l}\text { Participants used SNSs for an average of } 92 \text { minutes per day. Participants } \\
\text { experienced "near addiction" or "social media addiction" symptoms. }\end{array}$ \\
\hline $\begin{array}{l}\text { Hou, Xiong, Jiang, Song, } \\
\text { and Wang (2019) }\end{array}$ & China & 38 & Mean $=19.71$ & $\begin{array}{l}\text { An intervention, consisting of cognitive reconstruction, reminder cards and a diary } \\
\text { technique, was effective in reducing PSNSU severity and improving mental health } \\
\text { and academic efficiency. }\end{array}$ \\
\hline $\begin{array}{l}\text { Hussain, Simonovic, } \\
\text { Stupple, and Austin (2019) }\end{array}$ & UK & 69 & Mean $=23.09$ & $\begin{array}{l}\text { A negative association between openness to experience and inspection times for } \\
\text { the updates AOI, negative association between extraversion and inspection times } \\
\text { for social AOI. Increased duration of Facebook use was associated with increased } \\
\text { Facebook addiction severity scores and depression scores. }\end{array}$ \\
\hline $\begin{array}{l}\text { Leong, Hew, Ooi, Lee, and } \\
\text { Hew (2019) }\end{array}$ & Malaysia & 615 & NR & $\begin{array}{l}\text { A non-linear relationship between neuroticism and PSNSU severity. The artificial } \\
\text { neural network was able to predict PSNSU with an } 86.7 \% \text { accuracy. }\end{array}$ \\
\hline Meshi et al. (2020) & USA & $\begin{array}{l}\text { Study 1: } 105 \\
\text { Study 2: } 101 \\
\text { Study 3: } 123\end{array}$ & $\begin{array}{l}\text { Study } 1 \text { mean }=20.8 \\
\text { Study } 2 \text { mean }=20.3 \\
\text { Study } 3 \text { mean }=20.7\end{array}$ & A negative association between PSNSU severity and risk-taking. \\
\hline Turel and Serenko (2020) & USA & 220 & $\begin{array}{l}\text { Mean }=22.9 \\
\text { Range }=18-55\end{array}$ & $\begin{array}{l}\text { Implicit attitude is significantly positively associated with levels of PSNSU } \\
\text { severity in a magnitude similar to that observed for associations with substance } \\
\text { use. }\end{array}$ \\
\hline
\end{tabular}

AOI: areas of interest, FAD: Facebook addiction disorder, NR: not reported, PSNSU: Problematic social networking site use, SNSs: Social networking sites. 